\title{
Service Quality: \\ Pengembangan Instrumen Penilaian Jasa Layanan Pendidikan
}

\author{
Oleh: \\ Agustinus Februadi \\ Mukaram
Program Studi Manajemen Pemasaran, Jurusan Administrasi Niaga
Politeknik Negeri Bandung
Email: agustinus.februadi@ polban.ac.id

\begin{abstract}
Students' evaluations of teaching (SETs) have been an important and the most commonly used method for evaluating teaching quality in higher education institutions. They provide feedback from students to faculty and administrators. The majority SET instruments used in Indonesia were developed based on the faculty/administrators' knowledge and experience or adopted from other higher education institutions with or without modifications. This study aims to develop a SET instrument based on both educational theory and empirical data. Using data collected from a total of 755 students of Politeknik Negeri Bandung, the underlying dimensions and the psychometric properties of the instrument were tested. The exploratory factor analysis generated a three factor solution. A confirmatory factor analysis was then run to cross-validate the item indicators of each factor/dimension. The reliability and validity of the instrument were also tested. The final version of SET instrument encompasses 15 items in three dimensions. The three dimensions were labelled as preparation and organization (4 items), instructional delivery (7 items), and examination and feedback (4 items). Although it was developed using student samples from Politeknik Negeri Bandung, the newly developed instrument can be used in any higher education institutions.
\end{abstract}

\section{Pendahuluan}

Undang-Undang Nomor 12 Tahun 2012 Tentang Pendidikan Tinggi (UU Dikti) yang mengukuhkan Sistem Penjaminan Mutu Pendidikan Tinggi yang disingkat SPM Dikti. Tujuan dari SPM Dikti adalah untuk menjamin pemenuhan Standar Dikti secara sistemik dan berkelanjutan sehingga tumbuh dan berkembang budaya mutu di setiap perguruan tinggi di Indonesia (Dikti, 2014). SPM Dikti terdiri atas Sistem Penjaminan Mutu Internal (SPMI) dan Sistem Penjaminan Mutu Eksternal (SPME). SPMI adalah kegiatan sistemik penjaminan mutu pendidikan tinggi oleh setiap perguruan tinggi secara otonom atau mandiri untuk mengendalikan dan meningkatkan penyelenggaraan pendidikan tinggi secara berencana dan berkelanjutan. Sedangkan yang dimaksud dengan SPME adalah kegiatan penilaian melalui akreditasi untuk menentukan 
kelayakan program studi dan perguruan tinggi (Dikti, 2014).

Salah satu kegiatan yang dituntut oleh SMPI maupun SMPE adalah penilaian kinerja pengajaran dosen oleh mahasiswa atau di literatur lebih dikenal dengan sebutan student's evaluation of teaching (SET). Paling tidak ada dua alasan mengapa SET sangat diperlukan dalam rangka peningkatan mutu pendidikan. Pertama, kegiatan peningkatan mutu pendidikan akan berhasil jika mahasiswa, sebagai pihak yang dididik dan diajar, dilibatkan dalam kegiatan peningkatan mutu tersebut (Theall \& Franklin, 2001). Kedua, dilihat dari sudut pandang ilmu pemasaran jasa, proses pengajaran adalah proses penghantaran jasa dari pihak penyedia jasa (yang diwakili oleh dosen) kepada pihak konsumen (dalam kasus ini adalah mahasiswa). Menurut Zeithaml, Bitner \& Gremler (2010) pihak yang paling berkompeten dalam menilai kualitas suatu jasa adalah konsumen dari jasa itu sendiri. Dengan demikian pihak yang paling berkompeten dalam menilai kualitas jasa pengajaran seorang dosen adalah para mahasiswa yang diajar oleh dosen yang bersangkutan.

Dalam kaitannya dengan peningkatan mutu pendidikan, SET perlu dilakukan karena: 1) dapat memberikan umpan balik yang bersifat diagnostik untuk peningkatan berbagai aspek dalam penghantaran jasa pengajaran (Dodeen, 2013), 2) sebagai ukuran efektifitas pengajaran seorang dosen (Marsh, 2007), dan 3) sebagai salah satu komponen national and international quality assurance exercises (Marsh, 2007, p. 3). Dengan demikian kegiatan SET ini sangat penting untuk dilakukan secara teratur oleh semua perguruan tinggi di Indonesia sesuai dengan tuntutan SMPI dan SPME dalam rangka peningkatan mutu pendidikan di perguruan tinggi masing-masing.

Kegiatan SET sudah dilaksanakan diberbagai perguruan tinggi di Indonesia baik negeri maupun swasta. Akan tetapi instrumen SET yang digunakan biasanya dikembangkan sendiri berdasarkan pengetahuan dan pengalaman dosen atau sekelompok dosen yang ditunjuk. Sebagai contoh, dalam sepuluh tahun terakhir, Politeknik Negeri Bandung (POLBAN) menggunakan dua instrumen SET yang berbeda yang dikembangkan sendiri oleh tim dosen dengan cara meninjau instrumen instrumen SET yang sudah digunakan oleh perguruan tinggi lain. Akan tetapi, semua instrumen SET yang pernah digunakan di lingkungan POLBAN selama ini belum pernah diukur tingkat reliability dan validity-nya terutama dalam mengukur kualitas jasa pengajaran pada context pendidikan politeknik yang berbeda dengan pendidikan 
di universitas pada umumnya.

Penekanan penelitian ini adalah pada pengembangan instrumen SET yang dapat mengukur kualitas jasa pengajaran dosen sebagai bagian dari kegiatan peningkatan mutu pendidikan. Penelitian ini penting dilakukan bukan hanya untuk kepentingan peningkatan mutu pendidikan POLBAN tetapi juga untuk kepentingan peningkatan mutu pendidikan politeknik di seluruh Indonesia karena instrumen yang akan dihasilkan dapat diterapkan di politeknik-politeknik seluruh Indonesia yang pada dasarnya memiliki sistem pendidikan yang sama.

\section{Tinjauan pustaka}

Student's Evaluation of Teaching

Riset telah membuktikan bahwa jasa pengajaran dari dosen sangat berpengaruh terhadap pembelajaran mahasiswa (Sanders \& Rivers, 1996). Untuk mengetahui jasa pengajaran yang diberikan sudah efektif atau belum, pihak perguruan tinggi biasanya meminta penilaian dari mahasiswa tentang kualitas pengajaran yang sudah mereka dapat dengan menggunakan instrumen SET. Instrumen SET telah digunakan secara luas oleh sejumlah universitas di seluruh dunia untuk mengukur kualitas/efektifitas pengajaran dosen menurut mahasiswa (Pounder, 2007). Setelah meninjau literatur yang telah diterbitkan selama 50 puluh tahun ke belakang, McKeachie \& Kaplan (1996) berpendapat bahwa tidak ada alasan untuk meragukan SET yang mampu menghasilkan informasi yang valid dan berguna bagi dosen dan dekan. Hal ini didukung oleh Tamagori \& Bishop (1994) asalkan mahasiswa diberi pertanyaan yang tepat. Secara garis besar, penilaian (rating) mahasiswa cenderung statistically reliable, valid dan bebas dari bias dibanding penilaian dari rekan sejawat dan penilaian dari adminstrator akademik (Benton \& Cashin, 2012). Mahasiswa diyakini mampu memberikan umpan-balik yang berarti bagi dosen karena mereka telah banyak meluangkan waktu belajar (service encounter) bersama dosen (Tamagori \& Bishop, 1994). Dan yang mungkin lebih penting adalah hasil studi Murray (2005) yang menyimpulkan bahwa umpan-balik dari mahasiswa dapat membantu dosen untuk melakukan perbaikan-perbaikan dalam penghantaran jasa pengajarannya (service recovery). Perbaikan-perbaikan itu akan sangat bermanfaat jika dibarengi dengan konsultasi dengan seorang pakar pengajaran.

\section{Kritik terhadap SET}


Tetapi, penggunaan SET bukannya tanpa kekurangan. Dikatakan bahwa SET tidak dapat terhindar dari faktor-faktor yang turut mempengaruhi penilaian tetapi di luar kontrol dosen seperti: ukuran kelas, motivasi akademik mahasiswa, tingkat kesulitan mata kuliah, gender bias, senioritas dosen, usia dosen dan harapan mahasiswa terhadap nilai (Koh \& Tan, 1997; Pounder, 2007). SET juga diduga dapat mendorong para dosen untuk mudah memberi nilai tinggi agar mendapat penilaian yang baik dari mahasiswa (Murray, 2005). Ada juga yang berpendapat bahwa mahasiswa tidak memenuhi syarat untuk menilai beberapa aspek yang biasa dinilai dalam instrumen SET seperti the appropriateness of the instructor's objectives, relavansi tugas-tugas dan bahan bacaan, kemutakhiran isi mata kuliah, dan standar nilai dari dosen yang terlalu rendah atau terlalu tinggi (Benton \& Cashin, 2012). Walapun mempunyai kekurangan, kenyataannya, SET masih diberlakukan di banyak universitas di dunia dan masih dapat memberikan informasi yang berguna baik untuk tujuan formatif maupun summatif (Tee, Dawood, Kamala, Leong, \& Kuan, 2015). Tujuan formatif mengacu kepada hasil SET yang dipakai oleh dosen sebagai alat untuk mendiagnosa kinerja pengajarannya dan dari situ dosen berusaha untuk memperbaiki kekurangankekurangannya (service recovery). Tujuan summatif berhubungan dengan penentuan kenaikan jabatan/pangkat dosen (promosi jabatan) yang didasarkan pada hasil SET (Neumann, 2000).

\section{Manfaat SET}

Kegunaan SET untuk meningkatkan kinerja pengajaran dosen sudah dibuktikan diberbagai penelitian (Benton \& Cashin, 2012). Penelitian-penelitian terdahulu menunjukkan bahwa mengkombinasikan umpan-balik dengan konsultasi akan lebih bermanfaat dalam meningkatkan pengajaran dibandingkan hanya dengan umpan-balik saja (Hampton \& Reiser, 2004; Marincovich, 1999). Mendiskusikan hasil SET dengan rekan sejawat atau konsultan dapat meningkatkan kegunaannya (Aleamoni, 1978; Marsh \& Overall, 1979). Umpan-balik dan konsultasi yang ditujukan untuk mengatasi problem yang telah ditunjukkan oleh mahasiswa dan untuk memperbaiki perilaku pengajaran (teaching behaviour) tertentu terbukti memberikan dampak yang paling bermanfaat (Marsh \& Roche, 1993). Umpan-balik yang dianggap paling berguna bagi dosen adalah tentang: interaksi dengan mahasiswa, cara penilaian, dan global ratings of the course and instructor (Schmelkin, Spencer, \& Gellman, 1997). 
Umpan-balik yang diterima dosen bisa terasa sedikit merendahkan, tetapi umpan-balik itu dapat membantu dosen untuk menyadari bahwa ada sesuatu yang perlu diperbaiki pada pengajarannya (Weimer, 2009). Perubahan yang cukup berarti, menurut dosen yang telah mengalami peningkatan nilai yang signifikan pada end-of-course ratings, ternyata tidak membutuhkan upaya yang besar (McGowan \& Graham, 2009). Meningkatnya penilaian dari mahasiswa (perceived service) biasanya berhubungan dengan penggunaan active-learning di kelas, interaksi dosen - mahasiswa yang lebih baik, menuntut standar yang tinggi bagi mahasiswa, kesiapan mengajar, dan mengubah cara menilai tugas-tugas mahasiswa (McGowan \& Graham, 2009).

\section{Dimensi SET}

Seperti pengukuran kualitas jasa dari sudut pandang pemasaran yang melibatkan multidimensi (tangible, reliability, responsiveness, assurance, dan emphaty) (Parasuraman, Zeithaml, \& Malhotra, 2005), para peneliti dan praktisi pendidikan (Abrami \& d'Apollonia, 1991; Cashin \& Downey, 1992; Feldman, 1997; Marsh \& Roche, 1993) sepakat bahwa mengajar adalah aktifitas yang kompleks dengan faktorfaktor yang saling berkaitan satu sama lain seperti, kejelasan, interaksi, pengelolaan, antusiasme, dan umpan-balik. Jadi tidak mengherankan jika instrumen SET sebagai instrumen yang mengukur kualitas jasa pengajaran juga bersifat multidimensi. Banyaknya dimensi yang digunakan tergantung kepada bentuk pembelajaran dan jumlah item pertanyaan dalam instrumen (Benton \& Cashin, 2012). Dalam tinjauan pustakanya Feldman (2007) bahkan mengkategorikan SET ke dalam 28 dimensi. Student's Evaluations of Educational Quality (SEEQ) yang diciptakan oleh Marsh (2007) mempunyai sembilan dimensi. Hoyt \& Lee (2002) melaporkan adanya lima dimensi. Sementara, Braskamp \& Ory (1994) dan Centra (1993) keduanya mengidentifikasi enam dimensi yang biasa terdapat pada instrumen SET yaitu: 1) course organisation and planning; 2) clarity, communication skills; 3) teacher student interaction; 4) course difficulty, workload; 5) grading and examinations; dan 6) student self-rated learning. Dengan bervariasinya jumlah dimensi yang digunakan untuk mengukur kualitas jasa pengajaran, maka satu pemahaman yang bisa ditarik dari ke-multidimensi-an instrumen SET adalah "no single student ratings item or set of related items is usefull for all puposes" (Benton \& Cashin, 2012, p. 10).

\section{Pengembangan instrumen SET}

Mengenai proses pengembangan/pembuatan instrumen SET, Tamagori \& Bishop 
(1994) menyajikan pedoman sederhana. Mereka berpendapat bahwa proses pengembangan/pembuatan instrumen SET perlu melibatkan tiga elemen utama. Pertama, mengidentifikasi karakteristik dari jasa pengajaran yang efektif; kedua, membuat pertanyaan-pertanyaan berdasarkan dari karakteristik-karakteristik yang telah diidentifikasi; dan ketiga, memilih skala response yang paling tepat untuk setiap pertanyaan. Mereka juga mengingatkan bahwa proses pengembangan/pembuatan instrumen SET adalah proses yang panjang yang perlu direncanakan dan dirumuskan dengan seksama. Sebagai tambahan, Rowley (2003) mengusulkan lima faktor yang harus diperhatikan ketika mendisain instrumen SET: 1) adanya keseimbangan antara pertanyaan tentang pengajaran, support, sumber daya (resources) dan pembelajaran;

2) mendisain pertanyaan dengan tidak mengasumsikan satu moda pengajaran tertentu;

3) mendukung pembelajaran mandiri; 4) merefleksikan pengalaman mahasiswa dalam belajar, sehingga mahasiswa, secara anonim, bersedia memberi komentar yang jujur berdasarkan pengalamannya sendiri. Walaupun demikian, tidak satupun dari penulispenulis di atas yang menyajikan prosedur atau pedoman secara tahap demi tahap pengembangan/pembuatan instrumen SET.

\section{Rancangan penelitian}

Karena penelitian ini difokuskan pada pengembangan instrumen SET yang valid dan reliable untuk pendidikan politeknik, dengan mengacu kepada Spooren, Mortelmans, \& Denekens (2007) dan Dodeen (2013), maka proses pelaksanaan penelititan ini dilakukan dalam tiga tahap:

Tahap 1. Mengidentifikasi indikator pengajaran yang efektif

Pada tahap ini tinjauan pustaka (review of literature) tentang efektifitas pengajaran dilakukan dengan intensif. Studi-studi terdahulu tentang pengukuran efektifitas pengajaran juga ditelaah dengan seksama. Tujuan tahap ini adalah mengidentifikasi aspek-aspek penting dalam pengajaran yang efektif. Dari situ diharapkan item-item indikator jasa pengajaran yang efektif dapat diidentifikasi. Item-item tersebut kemudian akan ditinjau dari sisi content-related validity-nya.

Tahap 2. Menilai content-related validity

Sepuluh orang dosen senior (dengan latar belakang keilmuan yang berbeda dan pengalaman mengajar yang cukup panjang) dari sepuluh jurusan yang berbeda di POLBAN diundang untuk dilibatkan dalam kegiatan focus group discussion. Dalam focus group discussion ini para dosen senior meninjau semua item indikator jasa 
pengajaran yang efektif yang telah diidentifikasi pada tahap 1. Hasil dari tahap 2 ini adalah purwa-rupa instrumen SET yang siap untuk diuji construct-related validity and reliability-nya.

Tahap 3. Menilai construct-related validity and reliability

Pada tahap ini mahasiswa mulai dilibatkan. Total 755 orang mahasiswa dari berbagai tingkat dan program studi di POLBAN dilibatkan sebagai responden dan diminta untuk menjawab pertanyaan-pertanyaan pada purwa-rupa instrumen SET. Pilihan jawaban dari pertanyaan-pertanyaan tersebut berupa skala Likert lima titik dari 1 (sangat tidak setuju) sampai dengan 5 (sangat setuju). Pengambilan data dilakukan dua tahap. Pengambilan data tahap pertama dilakukan sebelum kegiatan akademik ujian tengah semester dilaksanakan. Pengambilan data tahap kedua dilakukan dua minggu setelah ujian tengah semester selesai dilaksanakan. Hasilnya berupa data yang akan dijadikan obyek untuk melakukan exploratory factor analysis (EFA). Tujuan melakukan EFA adalah: (1) EFA dilakukan untuk mengidentifikasi dimensi-dimensi atau faktor-faktor yang akan terbentuk berdasarkan pengelompokan item-item dalam purwa-rupa instrumen yang sedang dikembangkan. Dimensi-dimensi ini penting untuk diidentifikasi agar dapat dibandingkan dengan dimensi-dimensi serupa yang telah ada di literatur. (2) EFA dilakukan agar dapat menemukan item-item yang tidak termasuk ke dalam semua dimensi yang teridentifikasi, atau item-item yang memiliki factor loadings yang tinggi di beberapa dimensi sekaligus (cross-loading). Setelah EFA dilakukan maka selanjutnya dilakukan uji Cronbach's alpha. Uji ini dilakukan untuk memeriksa konsistensi dari semua item dalam satu dimensi.

Data hasil EFA dan uji Cronbach's alpha selanjutnya diolah dengan menggunakan metode confirmatory factor analysis (CFA). Metode ini dianggap sebagai "the best qualified to extensively test the validity and reliability of different scales" (Spooren et al., 2007 p. 672). Dari CFA dapat diketahui convergent validity dan discriminant validity masing-masing dimensi yang sudah teridentifikasi. Metode CFA ini menggunakan beberapa ukuran fit statistics. Salah satu diantaranya adalah chi-square test atau rasio chi-square terhadap degree of freedom $\left(\chi^{2} / d f<3.00\right) \cdot \chi^{2} / d f>3$ menandakan model yang poor fit (Hu \& Bentler, 1999; Tabachnick \& Fidell, 2007). Berhubung chi-square test sangat sensitif terhadap ukuran sampel, maka ukuran fit statistics yang tidak terpengaruh oleh ukuran sampel seperti Goodness of Fit Index (GFI > 0.90), Normed Fit Index (NFI >0.90), dan Comparative Fit Index (CFI > 0.90) 
akan digunakan pula. Hasil dari Tahap 3 ini adalah instrumen SET yang siap untuk implementasikan kepada para mahasiswa.

\section{Hasil penelitian}

Hasil tahap 1. Mengidentifikasi indikator pengajaran yang efektif

Pada tahap ini tinjauan pustaka (review of literature) tentang efektifitas pengajaran dilakukan dengan intensif. Studi-studi terdahulu tentang pengukuran efektifitas pengajaran juga ditelaah dengan seksama. Dari sekian banyak literatur yang ditinjau ditahap ini, Marsh (2007) dan OIRA (2014) merupakan literatur utama penelitian ini. Dari tahap ini dapat ditarik pemahaman tentang SET yaitu: 1) SET bersifat multidimensi, 2) dimensi-dimensi itu sangat beragam namun demikian dimensidimensi itu mengacu kepada antara lain: kejelasan, interaksi, persiapan, pengelolaan, antusiasme, luaran pada mahasiswa (student outcome), ujian dan umpan balik (Abrami \& d'Apollonia, 1991; Cashin \& Downey, 1992; Feldman, 1997; Marsh \& Roche, 1993). Dari berbagai literatur itu maka dipilih item-item indikator pengajaran yang efektif yang dikelompokkan berdasarkan dimensi-dimensinya. Indikator-indikator tersebut kemudian ditinjau dari sisi content-related validity-nya pada tahap dua.

Hasil tahap 2. Menilai content-related validity

Sepuluh orang dosen senior (dengan latar belakang keilmuan yang berbeda dan pengalaman mengajar yang cukup panjang) POLBAN diundang untuk terlibat dalam kegiatan focus group discussion. Dari sepuluh dosen yang diundang, enam orang dapat menghadiri kegiatan ini. Dalam focus group discussion ini para dosen diperkenalkan dengan maksud dan tujuan dari penelitian ini dan dijelaskan pula maksud dan tujuan kegiatan focus group discussion ini. Setelah itu para dosen diminta untuk meninjau semua item indikator jasa pengajaran yang efektif yang telah diidentifikasi pada tahap 1.

Hal yang ditinjau termasuk isi item, wording, kejelasan, kecocokan/ketepatan dengan pendidikan politeknik, hubungannya dengan item lain, dan hal-hal lain yang dapat membuat instrumen SET ini menjadi lebih baik. Dalam proses peninjauan ini terjadi diskusi yang intensif dan terjadi perubahan, penghapusan, pengurangan serta penambahan item item instrumen yang sedang dikembangkan. Dengan pertimbangan bahwa mengajar adalah aktifitas yang kompleks yang melibatkan berbagai 
faktor/dimensi yang saling berkaitan, kegiatan focus group discussion menghasilkan purwa-rupa instrumen SET yang terdiri dari 30 item indikator yang tergabung ke dalam enam dimensi. Keenam dimensi itu adalah: persiapan dan pengelolaan; penyajian kuliah; penjelasan materi; interaksi dosen-mahasiswa; luaran mahasiswa serta ujian dan umpan balik. Purwa-rupa instrumen SET ini siap untuk diuji constructrelated validity and reliability-nya di tahap tiga. Purwa-rupa instrumen SET itu dapat dilihat pada Tabel 1.

Tabel 1 - Purwa-rupa instrumen SET

\begin{tabular}{|c|c|c|}
\hline Dimensi Awal & No. & Item indikator \\
\hline \multirow{5}{*}{$\begin{array}{l}\text { Persiapan dan } \\
\text { pengelolaan }\end{array}$} & 1 & Dosen ybs menjelaskan tujuan dan rencana perkuliahan di awal semester \\
\hline & 2 & Dosen ybs terlihat sangat berpengetahuan/knowledgable tentang mata kuliah yang diajarkan \\
\hline & 3 & Dosen ybs terlihat mempersiapkan kuliah dengan baik \\
\hline & 4 & Kuliah dosen ybs disajikan secara teratur sesuai dengan jadwal \\
\hline & 5 & Dosen ybs memulai dan mengakhiri kuliah tepat waktu \\
\hline \multirow{5}{*}{ Penyajian kuiliah } & 6 & Dosen ybs mengacu pada buku ajar/textbook yang mutakhir \\
\hline & 7 & Dosen ybs menyajikan kuliah dengan cara yang menyenangkan/enjoyable \\
\hline & 8 & Dosen ybs menyajikan kuliah dengan antusias \\
\hline & 9 & Suasana kuliah dosen ybs mendorong mahasiswa untuk belajar \\
\hline & 10 & Dosen ybs memotivasi mahasiswa untuk belajar dengan lebih baik \\
\hline \multirow{4}{*}{ Penjelasan materi } & 11 & Materi perkuliahan dijelaskan dengan kecepatan yang tepat \\
\hline & 12 & Dosen ybs menjelaskan kembali materi perkuliahan yang sulit \\
\hline & 13 & Dosen ybs terlihat berusaha agar para mahasiswanya mengerti apa yang diajarkan \\
\hline & 14 & Dosen ybs memberi ilustrasi/contoh penerapan praktis dari teori/konsep yang diajarkan \\
\hline \multirow{5}{*}{$\begin{array}{l}\text { Interaksi dosen- } \\
\text { mahasiswa }\end{array}$} & 15 & Hubungan antara dosen ybs dengan mahasiswa memungkinkan terjadinya diskusi akademik yang baik \\
\hline & 16 & Anda merasa nyaman setiap kali berhubungan dengan dosen ybs \\
\hline & 17 & Dosen ybs mudah ditemui oleh mahasiswa selama jam kerja \\
\hline & 18 & Dosen ybs menyambut baik pertanyaan dari mahasiswa \\
\hline & 19 & Terhadap pertanyaan tersebut di atas, dosen ybs memberi tanggapan dengan baik \\
\hline \multirow{5}{*}{ Luaran mahasiswa } & 20 & Anda mengerti terhadap apa yang dijelaskan oleh dosen ybs dalam perkuliahan \\
\hline & 21 & Anda mendapat pengetahuan/keterampilan baru setelah mengikuti mata kuliah dosen ybs \\
\hline & 22 & Pengetahuan anda bertambah setelah mengikuti mata kuliah dosen ybs \\
\hline & 23 & Anda bersemangat untuk mengikuti kuliah dosen ybs \\
\hline & 24 & Untuk mata kuliah dosen ybs, anda belajar dengan rajin \\
\hline \multirow{6}{*}{$\begin{array}{l}\text { Ujian dan umpan } \\
\text { balik }\end{array}$} & 25 & Selain UTS dan UAS dosen ybs juga memberi quiz atau tugas-tugas lain yang dinilai \\
\hline & 26 & Materi UTS/UAS sesuai dengan materi yang telah diajarkan \\
\hline & 27 & Hasil ujian/quiz/tugas dibagikan tidak lama setelah ujian berlangsung \\
\hline & 28 & Dosen ybs memberi umpan balik terhadap ujian/quiz/tugas \\
\hline & 29 & Pemberian nilai dari dosen ybs dilakukan dengan transparan dan objektif \\
\hline & 30 & Secara garis besar bagaimana menurut anda kinerja dosen ybs dalam mengajar \\
\hline
\end{tabular}

Selain menghasilkan 30 item instrumen yang siap untuk diuji validity dan reliabilitynya, kegiatan focus group discussion ini juga mendiskusikan pengalaman dan kesankesan setelah menerima hasil SET yang telah dilakukan oleh POLBAN semester yang lalu. Para dosen itu kemudian mengidentifikasi beberapa hal yang sangat penting untuk dipertimbangkan ketika akan melaksanakan kegiatan pengukuran efektifitas pengajaran dosen yaitu:

1. Kegiatan pengukuran kualitas pengajaran dosen hanya bisa dilakukan kepada dosen tunggal suatu mata kuliah, dan tidak bisa dilakukan kepada dosen yang 
tergabung pada suatu team teaching.

2. Kegiatan pengukuran kualitas pengajaran dosen pada dosen-dosen team teaching akan menghasilkan penilaian yang bias mengingat pola pelaksanaan perkuliahan antara satu team teaching dengan team teaching lainnya sangat bervariasi dengan beban kerja yang berbeda-beda pula.

3. Dosen yang mengajar hanya di satu kelas cenderung akan mendapat hasil yang lebih baik dibanding dosen yang mengajar di beberapa kelas. Hal ini disebabkan karena dosen yang mengajar di satu kelas bisa lebih berkonsentrasi dan mencurahkan seluruh perhatiannya hanya pada satu kelas itu.

Hasil tahap 3. Menilai construct-related validity and reliability

\section{Pengambilan data tahap pertama.}

Pada pengambilan data tahap pertama ini sebanyak 398 orang mahasiswa dari 11 program studi yang berbeda di POLBAN dilibatkan sebagai responden dan diminta untuk menjawab pertanyaan-pertanyaan pada purwa-rupa instrumen SET.

Tabel 2 Karakteristik responden tahap 1

\begin{tabular}{|l|c|c|}
\hline \multicolumn{1}{|c|}{ Karakter mahasiswa } & Frekuensi & Persentase \\
\hline Semester 1 & 124 & 31.2 \\
\hline Semester 3 & 75 & 18.8 \\
\hline Semester 5 & 199 & 50.0 \\
\hline \multicolumn{1}{|c|}{ Jumlah } & $\mathbf{3 9 8}$ & $\mathbf{1 0 0}$ \\
\hline
\end{tabular}

Berhubung pada saat pengambilan data tahap pertama kegiatan akademik di POLBAN belum melaksanakan ujian tengah semester (UTS), maka purwa-rupa instrumen SET perlu dimodifikasi dengan menanggalkan 5 item yang tergabung dalam dimensi ujian dan umpan balik. Dengan demikian purwa-rupa instrumen SET yang digunakan pada pengambilan data tahap pertama ini terdiri dari 25 item (Lihat Tabel 3).

Tabel 3 Item indikator untuk pengambilan data tahap 1

\begin{tabular}{|c|c|l|}
\hline Faktor Awal & No. & \\
\hline \multirow{4}{*}{$\begin{array}{c}\text { Persiapan dan } \\
\text { pengelolaan }\end{array}$} & 1 & Dosen ybs menjelaskan tujuan dan rencana perkuliahan di awal semester. \\
\cline { 2 - 3 } & 2 & Dosen ybs terlihat sangat berpengetahuan/knowledgable tentang mata kuliah yang diajarkan. \\
\cline { 2 - 4 } & 3 & Dosen ybs terlihat mempersiapkan kuliah dengan baik. \\
\cline { 2 - 4 } & 4 & Kuliah dosen ybs disajikan secara teratur sesuai dengan jadwal. \\
\cline { 2 - 4 } & 5 & Dosen ybs memulai dan mengakhiri kuliah tepat waktu. \\
\hline & 6 & Dosen ybs mengacu pada buku ajar/textbook yang mutakhir. \\
\cline { 2 - 4 } & 7 & Dosen ybs menyajikan kuliah dengan cara yang menyenangkan/enjoyable.. \\
\hline
\end{tabular}




\begin{tabular}{|c|c|c|}
\hline \multirow{3}{*}{$\begin{array}{l}\text { Penyajian } \\
\text { kuiliah }\end{array}$} & 8 & Dosen ybs menyajikan kuliah dengan antusias. \\
\hline & 9 & Suasana kuliah dosen ybs mendorong mahasiswa untuk belajar. \\
\hline & 10 & Dosen ybs memotivasi mahasiswa untuk belajar dengan lebih baik. \\
\hline \multirow{4}{*}{$\begin{array}{l}\text { Penjelasan } \\
\text { materi }\end{array}$} & 11 & Materi perkuliahan dijelaskan dengan kecepatan yang tepat. \\
\hline & 12 & Dosen ybs menjelaskan kembali materi perkuliahan yang sulit. \\
\hline & 13 & Dosen ybs terlihat berusaha agar para mahasiswanya mengerti apa yang diajarkan. \\
\hline & 14 & Dosen ybs memberi ilustrasi/contoh penerapan praktis dari teori/konsep yang diajarkan. \\
\hline \multirow{5}{*}{$\begin{array}{c}\text { Interaksi dosen- } \\
\text { mahasiswa }\end{array}$} & 15 & Hubungan antara dosen ybs dengan mahasiswa memungkinkan terjadinya diskusi akademik yang baik. \\
\hline & 16 & Anda merasa nyaman setiap kali berhubungan dengan dosen ybs. \\
\hline & 17 & Dosen ybs mudah ditemui oleh mahasiswa selama jam kerja. \\
\hline & 18 & Dosen ybs menyambut baik pertanyaan dari mahasiswa. \\
\hline & 19 & Terhadap pertanyaan tersebut di atas, dosen ybs memberi tanggapan dengan baik. \\
\hline \multirow{6}{*}{$\begin{array}{c}\text { Luaran } \\
\text { mahasiswa }\end{array}$} & 20 & Anda mengerti terhadap apa yang dijelaskan oleh dosen ybs dalam perkuliahan. \\
\hline & 21 & Anda mendapat pengetahuan/keterampilan baru setelah mengikuti mata kuliah dosen ybs. \\
\hline & 22 & Pengetahuan anda bertambah setelah mengikuti mata kuliah dosen ybs. \\
\hline & 23 & Anda bersemangat untuk mengikuti kuliah dosen ybs. \\
\hline & 24 & Untuk mata kuliah dosen ybs, anda belajar dengan rajin. \\
\hline & 25 & Secara garis besar bagaimana menurut anda kinerja dosen ybs dalam mengajar. \\
\hline
\end{tabular}

Untuk mengidentifikasi dimensi yang terbentuk dari data tahap 1 ini, maka dilakukan exploratory factor analysis (EFA) dengan metode principal component dan Varimax rotation. Tes KMO menunjukan index sebesar 0.97 lebih tinggi dibanding nilai batas yang dapat diterima sebesar 0.6 menurut (Tabachnick \& Fidell, 2007). Bartlett test of sphericity menunjukkan nilai yang signifikan yang ditandai dengan $p<0.01$. Hal ini menunjukkan adanya korelasi yang besar antar variable. Dengan demikian factor analysis dapat dilakukan pada data yang ada.

KMO and Bartlett's Test

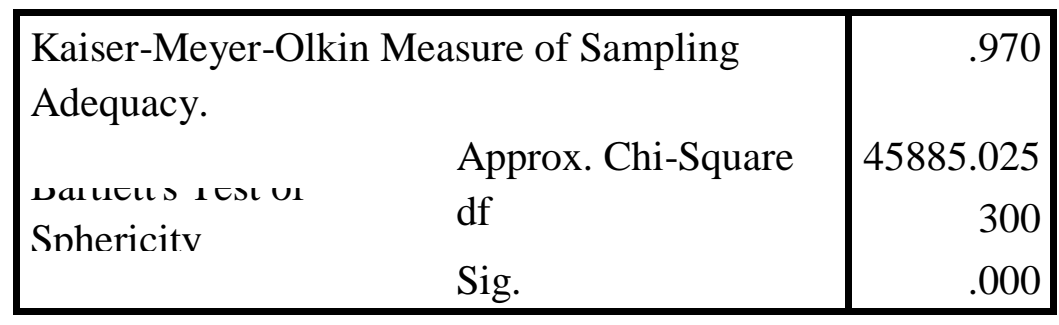

Dengan menggunakan kriteria Eigen value lebih besar atau sama dengan 1, analisis ini berhasil mengelompokkan item-item indikator ke dalam 2 faktor/dimensi. Pada analisis ini sebanyak 8 item tidak diikut sertakan dalam analisis secara satu per satu disebabkan karena cross-loading yang tinggi dan factor loading yang terlalu kecil. Kedelapan item itu adalah: Dosen ybs menjelaskan tujuan dan rencana perkuliahan di awal semester; Dosen ybs mengacu pada buku ajar/textbook yang mutakhir; Materi perkuliahan dijelaskan dengan kecepatan yang tepat; Dosen ybs memberi ilustrasi/contoh penerapan praktis dari teori/konsep yang diajarkan; Dosen ybs mudah ditemui oleh mahasiswa selama jam kerja; Dosen ybs menyambut baik 
pertanyaan dari mahasiswa; Terhadap pertanyaan tersebut di atas, dosen ybs memberi tanggapan dengan baik.

Kedua faktor yang dihasilkan EFA ini mampu menjelaskan 57.58 persen variance. Cumulative percentage of variance ini menunjukkan hasil yang dapat diterima karena lebih besar dari kriteria 50 persen seperti yang disarakan oleh Jöreskog \& Sörbom (1993). Factor loading, berkisar antara 0.603 sampai 0.808 , juga lebih besar dari kriteria yang dapat diterima 0.50 (Hair, Black, Babin, \& Anderson, 2010). Hal ini menunjukkan faktor yang terstruktur dengan baik. Cronbach alpha untuk faktor 1 (0.94) dan faktor 2 (0.78) lebih besar dari kriteria 0.70 (Nunnally, 1978). Hal ini berarti reliability yang baik.

Seperti terlihat pada Tabel 4.4, item-item yang mengelompok pada faktor 1 menunjukkan hal hal tentang pengajaran. Oleh karena itu, faktor 1 diberi nama Pengajaran. Sementara item-item yang mengelompok pada faktor 2 menunjukkan hal hal yang mengarah kepada persiapan dan pengelolaan perkuliahan. Oleh karena itu, faktor 2 diberi nama Persiapan dan Pengelolaan.

Tabel 4 Hasil analisis faktor tahap 1

\begin{tabular}{|l|l|c|}
\hline \multicolumn{1}{|c|}{ Item indikator } & \multicolumn{2}{c|}{ Faktor } \\
\cline { 2 - 3 } & Pengajaran & $\begin{array}{c}\text { Persiapan dan } \\
\text { pengelolaan }\end{array}$ \\
\hline Dosen sangat berpengetahuan/knowledgable tentang mata kuliah & & 0.625 \\
\hline Dosen mempersiapkan kuliah dengan baik. & & 0.714 \\
\hline Kuliah dosen ybs disajikan secara teratur sesuai dengan jadwal. & & 0.808 \\
\hline Dosen ybs memulai dan mengakhiri kuliah tepat waktu. & & 0.728 \\
\hline Dosen ybs menyajikan kuliah dengan cara yang menyenangkan/enjoyable. & 0.740 & \\
\hline Dosen ybs menyajikan kuliah dengan antusias. & 0.628 & \\
\hline Suasana kuliah dosen ybs mendorong mahasiswa untuk belajar. & 0.669 & \\
\hline Dosen ybs memotivasi mahasiswa untuk belajar dengan lebih baik. & 0.626 & \\
\hline Dosen ybs menjelaskan kembali bagian perkuliahan yang sulit. & 0.603 & \\
\hline Dosen ybs berusaha agar para mahasiswanya mengerti apa yang diajarkan. & 0.631 & \\
\hline Hubungan dosen-mahasiswa memungkinkan terjadinya diskusi akademik & 0.740 & \\
\hline Anda merasa nyaman setiap kali berhubungan dengan dosen ybs. & 0.772 & \\
\hline Anda mengerti apa yang dijelaskan oleh dosen ybs dalam perkuliahan. & 0.739 & \\
\hline Anda mendapat pengetahuan/keterampilan baru setelahikut mata kuliah dosen ybs. & 0.672 & \\
\hline Pengetahuan anda bertambah setelah mengikuti mata kuliah dosen ybs. & 0.655 & \\
\hline Anda bersemangat untuk mengikuti kuliah dosen ybs. & 0.792 & \\
\hline Untuk mata kuliah dosen ybs, anda belajar dengan rajin. & 0.673 & \\
\hline Secara garis besar bagaimana menurut anda kinerja dosen ybs dalam mengajar. & 0.691 & \\
\hline Variance explained (persen) & 38.77 & 18.82 \\
\hline Cumulative variance explained (persen) & & 57.58 \\
\hline Cronbach's alpha & 0.94 & 0.78 \\
\hline
\end{tabular}

\section{Pengambilan data tahap kedua}


Setelah mendapatkan 18 item yang reliable hasil dari exploratory factor analysis. Maka 5 item yang mengukur ujian dan umpan balik, yang tidak diukurkan pada pengambilan data tahap 1, ditambahkan sehingga menjadi purwa-rupa instrumen SET yang kedua yang terdiri dari 23 item (Lihat Tabel 5).

Tabel 5 Item indikator untuk pengambilan data tahap 2

\begin{tabular}{|c|c|}
\hline Faktor & Item indikator \\
\hline \multirow{4}{*}{$\begin{array}{c}\text { Persiapan dan } \\
\text { Pengelolaan }\end{array}$} & Dosen ybs terlihat sangat berpengetahuan/knowledgable tentang mata kuliah yang diajarkan. \\
\hline & Dosen ybs terlihat mempersiapkan kuliah dengan baik. \\
\hline & Kuliah dosen ybs disajikan secara teratur sesuai dengan jadwal. \\
\hline & Dosen ybs memulai dan mengakhiri kuliah tepat waktu. \\
\hline \multirow{14}{*}{ Pengajaran } & Dosen ybs menyajikan kuliah dengan cara yang menyenangkan/enjoyable. \\
\hline & Dosen ybs menyajikan kuliah dengan antusias. \\
\hline & Suasana kuliah dosen ybs mendorong mahasiswa untuk belajar. \\
\hline & Dosen ybs memotivasi mahasiswa untuk belajar dengan lebih baik. \\
\hline & Dosen ybs menjelaskan kembali bagian perkuliahan yang sulit. \\
\hline & Dosen ybs terlihat berusaha agar para mahasiswanya mengerti apa yang diajarkan. \\
\hline & Hubungan dosen ybs dengan mahasiswa memungkinkan terjadinya diskusi akademik yang baik. \\
\hline & Anda merasa nyaman setiap kali berhubungan dengan dosen ybs. \\
\hline & Anda mengerti terhadap apa yang dijelaskan oleh dosen ybs dalam perkuliahan. \\
\hline & Anda mendapat pengetahuan/keterampilan baru setelah mengikuti mata kuliah dosen ybs. \\
\hline & Pengetahuan anda bertambah setelah mengikuti mata kuliah dosen ybs. \\
\hline & Anda bersemangat untuk mengikuti kuliah dosen ybs. \\
\hline & Untuk mata kuliah dosen ybs, anda belajar dengan rajin. \\
\hline & Secara garis besar bagaimana menurut anda kinerja dosen ybs dalam mengajar. \\
\hline \multirow{5}{*}{$\begin{array}{c}\text { Item baru yang } \\
\text { ditambahkan }\end{array}$} & Selain UTS dan UAS dosen ybs juga memberi quiz atau tugas-tugas lain yang dinilai. \\
\hline & Materi UTS/UAS sesuai dengan materi yang telah diajarkan. \\
\hline & Hasil ujian/quiz/tugas dibagikan tidak lama setelah ujian berlangsung. \\
\hline & Dosen ybs memberi umpan balik terhadap ujian/quiz/tugas. \\
\hline & Pemberian nilai dari dosen ybs dilakukan dengan transparan dan objektif. \\
\hline
\end{tabular}

Sebanyak 357 mahasiswa POLBAN ikut serta dalam kegiatan pengisian kuesioner purwa-rupa instrumen SET tahap 2 ini. Semua mahasiswa responden pada tahap ini tidak ikut serta dalam pengambilan data tahap 1. Pengambilan data tahap 2 ini dilakukan dua minggu setelah kegiatan akademik ujian tengah semester (UTS) selesai dilaksanakan.

Tabel 6 Karakteristik responden tahap 2

\begin{tabular}{|l|c|c|}
\hline Karakter mahasiswa & Frekuensi & Persentase \\
\hline Semester 1 & 88 & 24.65 \\
\hline Semester 3 & 88 & 24.65 \\
\hline Semester 5 & 181 & 50.70 \\
\hline Jumlah & $\mathbf{3 5 7}$ & $\mathbf{1 0 0}$ \\
\hline
\end{tabular}


Untuk menguji apakah lima item yang baru ditambahkan akan membentuk faktor baru, dan menguji apakah dua faktor yang sudah terbentuk pada EFA tahap pertama tetap stabil. Maka pada data tahap 2 juga dilakukan exploratory factor analysis dengan metode principal component dengan varimax rotation.

\section{KMO and Bartlett's Test}

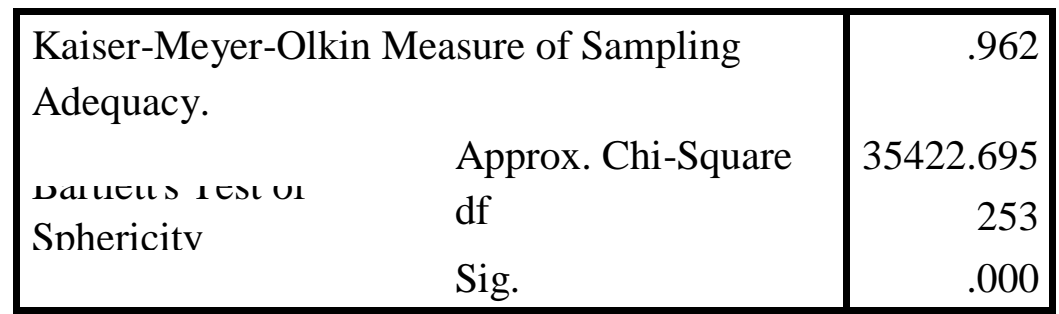

KMO tes menunjukkan index 0.962 yang berarti lebih tinggi dari batas yang dapat diterima 0.60 seperti yang disarankan oleh Tabachnick \& Fidell (2007). Bartlett's test of sphericity mempunyai nilai yang signifikan $(\mathrm{p}<0.01)$. KMO tes dan Bartlett tes ini mengindikasikan bahwa analisis faktor dapat dilakukan pada data yang ada. Proses selanjutnya dalam analisis ini meminta untuk membuang dua item secara satu persatu disebabkan oleh cross-loading yang tinggi dan factor loading yang terlalu rendah. Kedua item itu adalah: Secara garis besar bagaimana menurut anda kinerja dosen ybs dalam mengajar dan Dosen ybs menyajikan kuliah dengan antusias.

Analisis principal component mengelompokkan item-item ke dalam 3 faktor yang dapat menjelaskan 58.325 persen total variance. Angka persentase ini mengindikasikan hasil yang dapat diterima karena lebih besar dibanding batas bawah 50 persen seperti yang direkomendasikan Jöreskog \& Sörbom (1993). Factor loading berkisar antara 0.456 sampai 0.778 juga lebih besar dibanding batas bawah 0.40 (Hair et al., 2010). Sebagai tambahan, nilai Cronbach alpha untuk ketiga faktor, 0.934; 0.795; 0.777, juga lebih besar dari batas bawah 0.70 seperti yang disarankan oleh Nunnally (1978).

Dari ketiga faktor yag terbentuk menunjukkan kestabilan faktor Pengajaran, karena item-item yang membentuk faktor Pengajaran di tahap 1 masih tetap berkelompok membentuk faktor Pengajaran di tahap 2 ini. Begitu juga dengan faktor Persiapan dan pengelolaan. Item-item pembentuk faktor ini tidak berubah sama sekali di tahap 2 ini, Hal ini menunjukkan kestabilan faktor tersebut. Lima item baru yang berhubungan 
dengan masalah ujian dan umpan balik juga mengelompok dan membentuk satu faktor baru yang diberi nama Ujian dan umpan balik. Dengan demikian ketiga faktor itu adalah Persiapan dan pengelolaan, Pengajaran, dan Ujian dan umpan balik (Tabel 7)

Tabel 7 Hasil analisis faktor tahap 2

\begin{tabular}{|c|c|c|c|}
\hline \multirow[b]{2}{*}{ Item indikator } & \multicolumn{3}{|c|}{ Faktor } \\
\hline & Pengajaran & $\begin{array}{c}\text { Persiapan } \\
\text { dan } \\
\text { pengelolaan }\end{array}$ & $\begin{array}{l}\text { Ujian dan } \\
\text { umpan balik }\end{array}$ \\
\hline Dosen ybs terlihat sangat berpengetahuan/knowledgable tentang mata kuliah yang diajarkan & & 0.716 & \\
\hline Dosen ybs terlihat mempersiapkan kuliah dengan baik & & 0.706 & \\
\hline Kuliah dosen ybs disajikan secara teratur sesuai dengan jadwal & & 0.736 & \\
\hline Dosen ybs memulai dan mengakhiri kuliah tepat waktu & & 0.646 & \\
\hline Dosen ybs menyajikan kuliah dengan cara yang menyenangkan/enjoyable & 0.729 & & \\
\hline Suasana kuliah dosen ybs mendorong mahasiswa untuk belajar & 0.717 & & \\
\hline Dosen ybs memotivasi mahasiswa untuk belajar dengan lebih baik & 0.704 & & \\
\hline Dosen ybs menjelaskan kembali bagian perkuliahan yang sulit & 0.584 & & \\
\hline Dosen ybs terlihat berusaha agar para mahasiswanya mengerti apa yang diajarkan & 0.640 & & \\
\hline Hubungan dosen ybs dengan mahasiswa memungkinkan terjadinya diskusi akademik yang baik & 0.696 & & \\
\hline Anda merasa nyaman setiap kali berhubungan dengan dosen ybs & 0.751 & & \\
\hline Anda mengerti terhadap apa yang dijelaskan oleh dosen ybs dalam perkuliahan & 0.739 & & \\
\hline Anda mendapat pengetahuan/keterampilan baru setelah mengikuti mata kuliah dosen ybs & 0.601 & & \\
\hline Pengetahuan anda bertambah setelah mengikuti mata kuliah dosen ybs & 0.608 & & \\
\hline Anda bersemangat untuk mengikuti kuliah dosen ybs & 0.778 & & \\
\hline Untuk mata kuliah dosen ybs, anda belajar dengan rajin & 0.637 & & \\
\hline Selain UTS dan UAS dosen ybs juga memberi quiz atau tugas -tugas lain yang dinilai & & & 0.599 \\
\hline Materi UTS/UAS sesuai dengan materi yang telah diajarkan & & & 0.456 \\
\hline Hasil ujian/quiz/tugas dibagikan tidak lama setelah ujian berlangsung & & & 0.765 \\
\hline Dosen ybs memberi umpan balik terhadap ujian/quiz/tugas & & & 0.727 \\
\hline Pemberian nilai dari dosen ybs dilakukan dengan transparan dan objektif & & & 0.682 \\
\hline Variance explained (persen) & 29.843 & 14.445 & 14.037 \\
\hline Cumulative variance explained (persen) & & & 58.325 \\
\hline Cronbach's alpha & 0.934 & 0.795 & 0.777 \\
\hline
\end{tabular}

\section{Confirmatory Factor Analysis}

Setelah dilakukan exploratory factor analysis, selanjutnya dilakukan confirmatory factor analysis (CFA). Tujuan dilakukannya CFA adalah untuk memastikan kekhasan (berbeda dengan yang lain) masing masing faktor dan juga untuk memastikan discriminant validity ketiga faktor tersebut. 


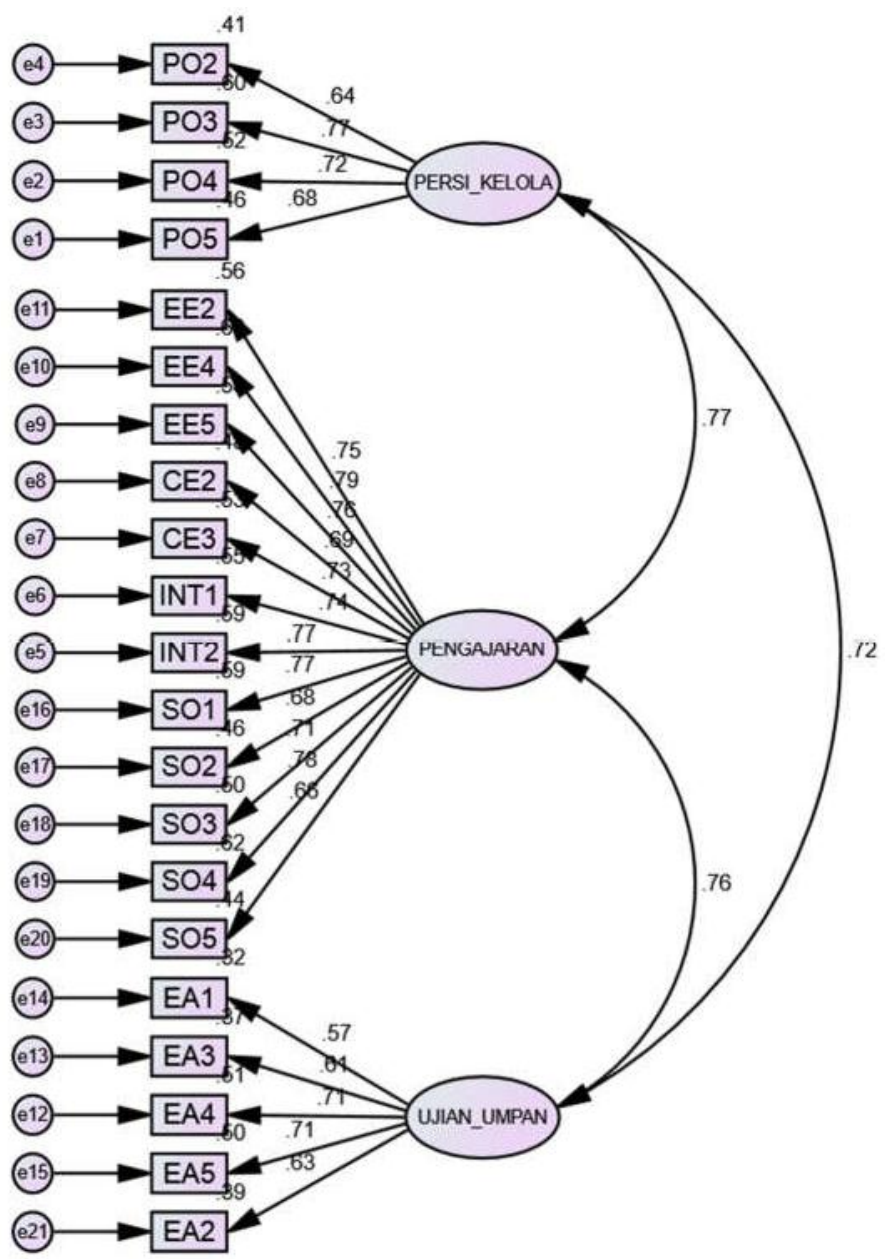

Gambar 4.1 CFA awal semua faktor

Hasil CFA awal menunjukkan data yang tidak begitu fit terhadap model dengan $\chi^{2}=$ $3175.983 p=0.000, \chi^{2} / \mathrm{df}=17.075, \mathrm{GFI}=0.892, \mathrm{AGFI}=0.866, \mathrm{NFI}=0.896, \mathrm{TLI}=$ $0.889, \mathrm{CFI}=0.901, \mathrm{RMSEA}=0.078$, and $\mathrm{SRMR}=0.0411$. Setelah index modifikasi pada model diperiksa, terdapat measurement error dari beberapa item saling berkorelasi tinggi. Oleh karena itu model perlu dimodifikasi dengan membuang itemitem yang measurement error-nya berkorelasi tinggi. Item-item itu adalah: Anda mendapat pengetahuan/keterampilan baru setelah mengikuti mata kuliah dosen ybs; Dosen ybs memotivasi mahasiswa untuk belajar dengan lebih baik; Dosen ybs terlihat berusaha agar para mahasiswanya mengerti apa yang diajarkan; Anda merasa nyaman setiap kali berhubungan dengan dosen ybs; Untuk mata kuliah dosen ybs, anda belajar dengan rajin. Pembuangan lima item yang bermasalah telah mengubah jumlah item pada faktor Pengajaran dari 12 menjadi tujuh item. Sedangkan faktor Persiapan dan pengelolaan tetap empat item. Faktor Ujian dan umpan balik berubah 
dari lima menjadi empat item.

Setelah model dimodifikasi, maka data menjadi lebih fit terhadap model dibanding model awal. Hal ini ditunjukkan oleh $\chi^{2}=730.659, p=0.000, \chi^{2} / \mathrm{df}=8.398$, GFI $=$ $0.964, \mathrm{AGFI}=0.950, \mathrm{NFI}=0.960, \mathrm{TLI}=0.957, \mathrm{CFI}=0.964, \mathrm{RMSEA}=0.053$, dan SRMR $=0.0315$. Pemeriksaan pada Gambar 4.2 menunjukkan semua faktor mempunyai nilai factor loading lebih besar (berkisar $0.56-0.78$ ) dibanding nilai minimum 0.40 seperti direkomendasikan oleh Tabachnick \& Fidell (2007). Lebih lanjut, koefisien korelasi antar faktor semuanya di bawah nilai maksimum 0.85 (Kline, 2005), hal ini menunjukkan kekhasan (distinctiveness) dari masing masing faktor.

Gambar 4.2 CFA akhir semua faktor

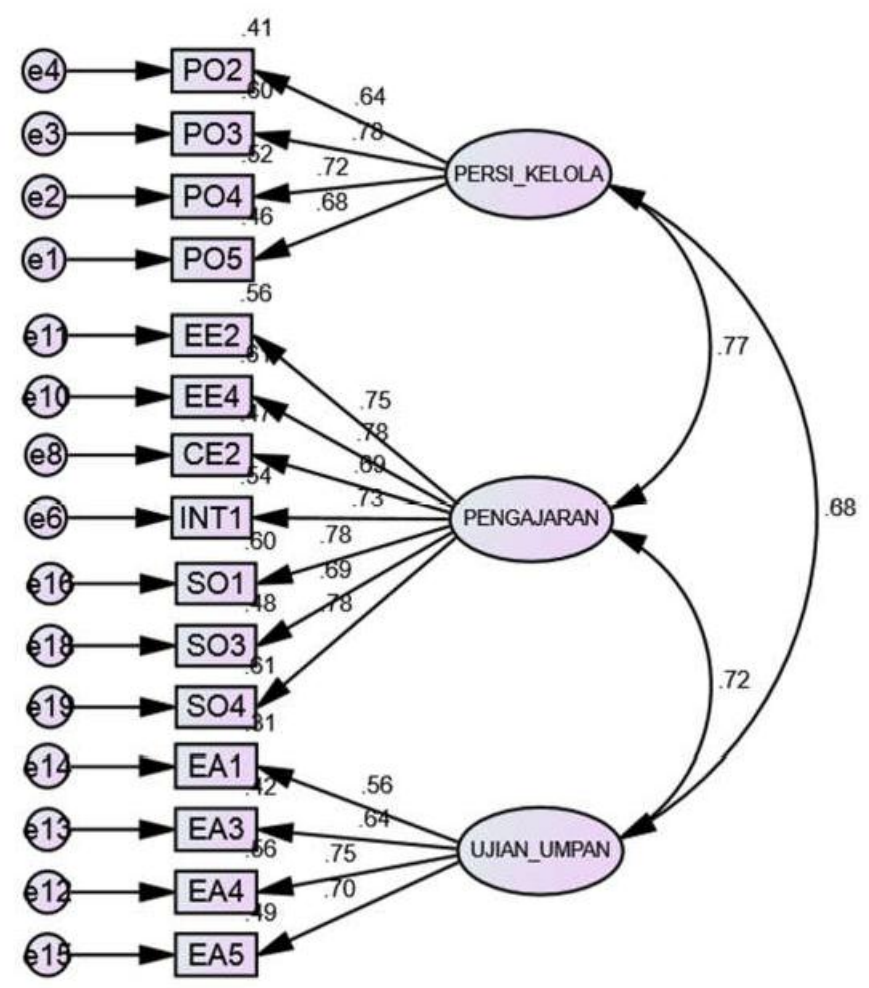

\section{Reliability dan validity}

Pada penelitian ini reliability faktor-faktor yang terbentuk diukur dengan Cronbach's alpha dan construct reliability (CR) seperti yang disarankan oleh Fornell \& Larcker (1981). Tabel 8 menunjukkan nilai Cronbach's alpha untuk ketiga faktor berada di atas batas bawah 0.70. Construct reliability ketiga faktor juga di atas batas minimum 0.60. Hal ini menunjukkan bahwa ketiga faktor tersebut reliable. 
Tabel 8 Reliability test

\begin{tabular}{|c|c|c|c|c|}
\hline \multirow{2}{*}{ Faktor } & \multirow{2}{*}{ Item } & \multicolumn{2}{|c|}{ Standardised Cronbach } & \multirow{2}{*}{ CR } \\
\hline & & loading & alpha & \\
\hline \multirow{4}{*}{$\begin{array}{c}\text { Persiapan dan } \\
\text { pengelolaan }\end{array}$} & PO2 & 0.643 & \multirow{4}{*}{0.795} & \multirow{4}{*}{0.846} \\
\hline & PO3 & 0.776 & & \\
\hline & PO4 & 0.720 & & \\
\hline & PO5 & 0.675 & & \\
\hline \multirow{7}{*}{ Pengajaran } & EE2 & 0.749 & \multirow{7}{*}{0.895} & \multirow{7}{*}{0.911} \\
\hline & EE4 & 0.780 & & \\
\hline & CE2 & 0.689 & & \\
\hline & INT1 & 0.734 & & \\
\hline & SO1 & 0.776 & & \\
\hline & $\mathrm{SO} 3$ & 0.690 & & \\
\hline & $\mathrm{SO} 4$ & 0.782 & & \\
\hline \multirow{4}{*}{$\begin{array}{c}\text { Ujian dan } \\
\text { umpan balik }\end{array}$} & EA1 & 0.561 & \multirow{4}{*}{0.753} & \multirow{4}{*}{0.746} \\
\hline & EA3 & 0.644 & & \\
\hline & EA4 & 0.748 & & \\
\hline & EA5 & 0.701 & & \\
\hline
\end{tabular}

Validity dari faktor-faktor dalam penelitian ini diukur dengan convergent dan discriminant validity. Covergent validity dapat tercapai jika factor loading ketiga faktor berbeda secara signifikan dari nol (Anderson \& Gerbing, 1988; Holmes-Smith, 2013). Tabel 8 menunjukkan semua standardised loading lebih besar dari 0.60 dan signifikan secara statistik. Hal ini berarti convergent validity telah tercapai.

Discriminat validity dapat dimiliki oleh ketiga faktor jika korelasi antar faktor tidak terlalu tinggi (misalnya < 0.85) (Anderson \& Gerbing, 1988; Kline, 2005). Seperti dapat dilihat pada Tabel 9 semua korelasi antar faktor lebih kecil dari 0.85. dengan demikian ketiga faktor tersebut bisa dikatakan valid.

Tabel 9 Matriks korelasi antar faktor

\begin{tabular}{|l|c|c|c|}
\hline \multicolumn{1}{|c|}{ Faktor } & 1 & 2 & 3 \\
\hline Persiapan dan pengelolaan & 1.00 & & \\
\hline Pengajaran & 0.77 & 1.00 & \\
\hline Ujian dan umpan balik & 0.68 & 0.72 & 1.00 \\
\hline
\end{tabular}

\section{Instrumen SET versi terakhir}

Hasil akhir dari CFA adalah item-item indikator kualitas pengajaran yang reliable dan 
valid dan menjadi instrumen SET yang siap untuk di aplikasikan di lingkungan politeknik. Instrumen SET ini terdiri dari 15 item yang terkelompokan ke dalam tiga faktor/dimensi yaitu: Persiapan dan pengelolaan, Pengajaran, dan Ujian dan umpan balik. Tabel 10 di bawah ini menunjukkan instrumen SET tersebut.

Tabel 10 Instrument SET

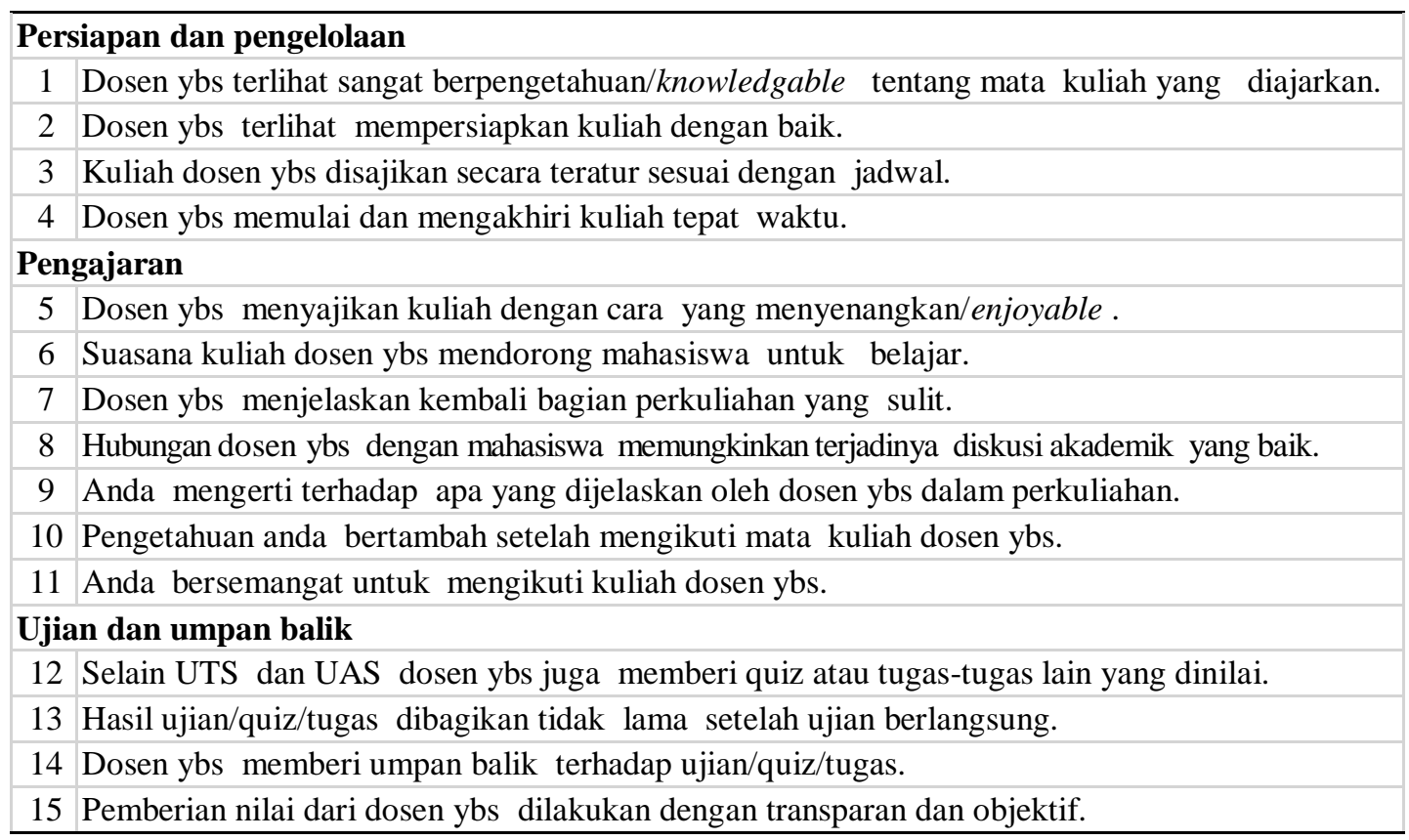

\section{Pembahasan}

Hasil penelitian ini sesuai dengan apa yang sudah ditulis diliteratur yaitu SET bersifat mulidimensi (Braskamp \& Ory, 1994; Centra, 1993; Hoyt \& Lee, 2002; Marsh, 2007). Sejumlah penelitian juga telah mengidentifikasi berbagai dimensi dari SET. Diantaranya, Toland \& De Ayala (2005) mengidentifikasi tiga dimensi: penyajian kuliah, interaksi dosen-mahasiswa dan peraturan kuliah. Gursoy \& Umbreit (2005) menemukan empat dimensi, yaitu: pembelajaran, pengelolaan, penyajian kuliah, dan beban kerja. Sementara Marks (2000) berhasil mengidentifikasi lima dimensi: pengelolaan, tingkat kesulitan, penilaian, kepedulian dosen dan pembelajaran. Dimensi pengelolaan, interaksi dosen-mahasiswa dan penilaian nampaknya tiga dimensi yang selalu ada pada berbagai instrumen SET (Dodeen, 2013).

Dengan membandingkan hasil penelitian ini dengan literatur, dapat dilihat bahwa ketiga dimensi yang teridentifikasi dalam penelitian ini tidak jauh berbeda dengan hasil studi lainnya. Dimensi persiapan dan penglolaan dalam penelitian ini merupakan dimensi yang mengukur tentang persiapan dan pengelolaan perkuliahan oleh dosen. 
Dimensi pengajaran berisi item-item yang mengukur penyajian kuliah, penjelasan materi, interaksi dosen-mahasiswa dan luaran mahasiswa. Sedangkan dimensi ujian dan umpan balik mengukur tentang penilaian dan umpan balik dari dosen.

\section{Rangkuman}

Penilaian kinerja pengajaran dosen oleh mahasiswa atau di literatur lebih dikenal dengan sebutan student's evaluation of teaching (SET) merupakan bagian dari kegiatan peningkatkan mutu pendidikan di perguruan tinggi. Alasan mengapa SET sangat diperlukan adalah: 1) kegiatan peningkatan mutu pendidikan akan berhasil jika mahasiswa dilibatkan dalam kegiatan peningkatan mutu tersebut (Theall \& Franklin, 2001), 2) pihak yang paling berkompeten dalam menilai kualitas jasa pengajaran seorang dosen adalah para mahasiswa yang diajar oleh dosen yang bersangkutan.

Berdasarkan kajian pustaka dan focus group didapat 30 item indikator untuk menilai pengajaran dosen yanq efektif. Dengan melalui proses exploratory factor analysis dan confirmatory factor analysis, dihasilkan instrumen SET yang terdiri dari 15 item indikator dan telah diuji reliability dan validity. Instrumen SET ini hanya untuk menilai kinerja pengajaran dosen tunggal dan bukannya dosen dalam kelompok team teaching. Instrumen SET yang dihasilkan telah siap untuk diaplikasikan di perguruan tinggi politeknik khususnya. Penelitian lanjutan masih diperlukan untuk lebih memurnikan (refine) kemampuan instrumen SET ini dalam mengukur kualitas pengajaran dosen dengan menggunakan sampel yang berbeda dari intitusi pendidikan tinggi yang berbeda pula.

\section{Daftar Pustaka}

Abrami, P. C., \& d'Apollonia, S. (1991). Multidimensional students' evaluations of teaching effectiveness: Generalizability of $\mathrm{N}=1$ research, Comment on Marsh (1991). Journal of Educational Psychology, 30, 221-227.

Aleamoni, L. M. (1978). The usefulness of student evaluations in improving college teaching. Instructional Science, 7, 95-105.

Anderson, J. C., \& Gerbing, D. W. (1988). Structural equation modeling in practice: A review and recommended two-step approach. Psychological Bulletin, 103(3), 411-423.

Benton, S. L., \& Cashin, W. E. (2012) Student ratings of teaching: A summary of research and literature. Vol. 50. IDEA Paper \# 50: The IDEA Center.

Braskamp, L. A., \& Ory, J. C. (1994). Assessing faculty work: Enhancing individual and institutional performance. San Fransisco: Jossey-Bass.

Cashin, W. E., \& Downey, R. G. (1992). Using global student rating items for summative evaluation. Journal of Educational Psychology, 84(563-572).

Centra, J. A. (1993). Refelective faculty evaluation. San Fransisco, CA: Jossey-Bass.

Dikti, D. D. (2014). Pedoman Sistem Penjaminan Mutu Pendidikan Tinggi. Jakarta: 
Direktorat Pembelajaran dan Kemahasiswaan, Direktorat Jenderal Pendidikan Tinggi, Kementerian Pendidikan dan Kebudayaan.

Dodeen, H. (2013). College students' evaluation of effective teaching: Developing an instrument and assessing its psychometric properties. Research in Higher Education Journal, 21, 1-12.

Feldman, K. A. (1997). Identifying exemplary teachers and teaching: Evidence from student ratings. In R. P. Perry \& J. C. Smart (Eds.), Effective Teaching in Higher Education: Research and Practice. New York: Agathon Press

Feldman, K. A. (2007). Identifying exemplary teachers and teaching: Evidence from student ratings. In R. P. Perry \& J. C. Smart (Eds.), The Scholarship of teaching and learning in higher education: An evidence-based perspective. Dordrecht, The Netherlands: Springer

Fornell, C., \& Larcker, D. F. (1981). Evaluating structural equation models with unobservable variables and measurement error. Journal of Marketing Research, 18(1), 39-50.

Gursoy, D., \& Umbreit, W. T. (2005). Exploring students' evaluations of teaching effectiveness: What factors are important? Journal of Hospitality \& Tourism Research, 29(1), 91-109.

Hair, J. F., Black, W. C., Babin, B., \& Anderson, R. E. (2010). Multivariate data analysis (7th ed.). New Jersey: Pearson.

Hampton, S. E., \& Reiser, R. A. (2004). Effects of theory-based feedback and consultation process on instruction and learning in cillege classrooms. Research in Higher Education, 45, 497-527.

Holmes-Smith, P. (2013). Structural equation modelling: From the fundamentals to advanced topics. Melbourne: SREAMS.

Hoyt, D. P., \& Lee, E. (2002). IDEA Technical Report No. 12: Basic Data for the Revised IDEA System. Manhattan, KS: The IDEA Center.

Hu, L. t., \& Bentler, P. M. (1999). Cutoff criteria for fit indexes in covariance structure analysis: Conventional criteria versus new alternatives. Structural Equation Modeling: A Multidisciplinary Journal, 6(1), 1-55.

Jöreskog, K. G., \& Sörbom, D. (1993). LISREL 8: Structural equation modeling with the SIMPLIS command language. Lincolnwood, IL: Scientific Software International.

Kline, R. B. (2005). Principles and practice of structural equation modeling. New York: Guilford Press.

Koh, H. C., \& Tan, T. M. (1997). Empirical investigation of the factors affecting SET results. International Journal of Educational Management, 11(4), 170-178.

Marincovich, M. (1999). Using student feedback to improve teaching. In P. Seldin (Ed.), Changing practices in evaluating teaching: A practical guide to improve faculty performance and promotion/tenure decisions (pp. 45-69). Bolton, MA: Anker

Marks, R. B. (2000). Determinants of student evaluations of global measures of instructor and course value. Journal of Marketing Education, 22(2), 108-119.

Marsh, H. W. (2007). Students' evaluations of university teaching: Dimensionality, reliability, validity, potential biases and usefulness. In R. P. Perry \& J. C. Smart (Eds.), The scholarship of teaching and learning in higher education: An evidence-based perspective (pp. 319-383). New York: Springer

Marsh, H. W., \& Overall, J. U. (1979). Long-term stability of student's evaluations: A note on Feldman's consistency and variability among college students in rating 
their teachers and courses. Research in Higher Education, 10, 139-147.

Marsh, H. W., \& Roche, L. A. (1993). The use of student's evaluations and an indivisual structured intervention to enhance university teaching effectiveness. American Educational Research Journal, 30, 217-251.

McGowan, W. R., \& Graham, C. R. (2009). Factors contributing to improved teaching performance. Innovative Higher Education, 34, 161-171.

McKeachie, W., \& Kaplan, M. (1996). Persistent problems in eveluating college teaching. AAHE, 48(6), 5-8.

Murray, H. G. (2005). Student evaluation of teaching: Has it made a difference. Paper presented at the Annual Meeting of the Society for Teaching and Learning in Higher Education, Charlottetown. Prince Edward Island.

Neumann, R. (2000). Communicating student evaluation of teaching results: rating interpretation guides (RIGs). Assessment \& Evaluation in Higher Education, 25(2), 121-134.

Nunnally, J. (1978). Psychometric theory. New York: McGraw-Hill.

OIRA. (2014). Student ratings of teaching effectiveness: using the OIRA item bank to create your own form Retrieved from http://oira.syr.edu/wpcontent/uploads/2014/12/ItemBankManual.pdf

Parasuraman, A., Zeithaml, V. A., \& Malhotra, A. (2005). ES-QUAL a multiple-item scale for assessing electronic service quality. Journal of service research, 7(3), 213-233.

Pounder, J. S. (2007). Is student evaluation of teaching worthwhile? An analytical framework for answering the question. Quality Assurance in Education, 15(2), $178-191$.

Rowley, J. (2003). Designing student feedback questionnaires. Quality Assurance in Education, 11(3), 142-149.

Sanders, L. W., \& Rivers, J. C. (1996). cumulative and residual effects of teachers on future student academic achievement. Knoxville, TN: University of Tennessee.

Schmelkin, L. P., Spencer, K. J., \& Gellman, E. S. (1997). Faculty perspective on course and teacher evaluations. Research in Higher Education, 38, 575-592.

Spooren, P., Mortelmans, D., \& Denekens, J. (2007). Student evaluation of teaching quality in higher education: development of an instrument based on 10 Likertscales. Assessment \& Evaluation in Higher Education, 32(6), 667-679.

Tabachnick, B. G., \& Fidell, L. S. (2007). Using multivariate statistics (5th ed.). Boston: Pearson/Allyn \& Bacon.

Tamagori, H., \& Bishop, L. (1994). Content analysis of evaluation instruments used for student evaluation of classroom teaching performance in higher education. Paper presented at the The Annual Meeting of the American Educational Research Association, New Orleans, LA.

Tee, M. Y., Dawood, F. K. P., Kamala, M., Leong, S. J., \& Kuan, C. H. (2015). Designing an instrument for providing better student feedback on teaching effectiveness. The Malaysian Online Journal of Educational Science, 3(1).

Theall, M., \& Franklin, J. (2001). Looking for bias in all the wrong places: a search for truth or a witch hunt in student ratings of instruction? New Directions for Institutional Research, 2001(109), 45-56.

Toland, M. D., \& De Ayala, R. (2005). A multilevel factor analysis of students' evaluations of teaching. Educational and Psychological Measurement, 65(2), 272-296.

Weimer, M. (2009). Teachers who improved. The Teaching Professor, 32(2). 
Zeithaml, V. A., Bitner, M. J., \& Gremler, D. D. (2010). Services marketing strategy: Wiley Online Library. 